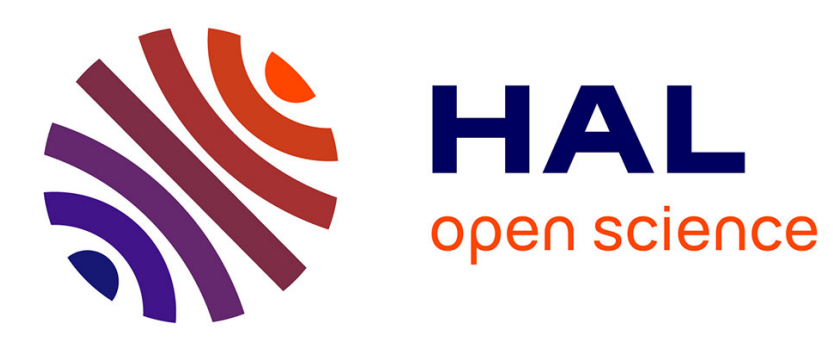

\title{
Kinetic study of a HGdP2O7.3H2O dehydration step
}

Haikel Galai, Françoise Valdivieso, Michèle Pijolat, Malika Trabelsi-Ayadi

\section{To cite this version:}

Haikel Galai, Françoise Valdivieso, Michèle Pijolat, Malika Trabelsi-Ayadi. Kinetic study of a HGdP2O7.3H2O dehydration step. Thermochimica Acta, 2004, 428 (1-2), pp.105-111. 10.1016/j.tca.2004.10.009 . hal-00409167

\section{HAL Id: hal-00409167 https://hal.science/hal-00409167}

Submitted on 6 Aug 2009

HAL is a multi-disciplinary open access archive for the deposit and dissemination of scientific research documents, whether they are published or not. The documents may come from teaching and research institutions in France or abroad, or from public or private research centers.
L'archive ouverte pluridisciplinaire HAL, est destinée au dépôt et à la diffusion de documents scientifiques de niveau recherche, publiés ou non, émanant des établissements d'enseignement et de recherche français ou étrangers, des laboratoires publics ou privés. 


\title{
Kinetic study of a $\mathrm{HG}_{2} \mathrm{PP}_{2} \mathrm{O}_{7} \cdot 3 \mathrm{H}_{2} \mathrm{O}$ dehydration step
}

\section{H.GALAI (1) , F.VALDIVIESO (2), M.PIJ OLAT (2) AND M.TRABELSI-AYADI (1)}

(1) Faculté des Sciences de Bizerte, Département de Chimie, 7021 Zarzouna, Bizerte, Tunisie

(2) LPMG, CNRS UMR 5148, Centre SPIN, Ecole Nationale Supérieure des Mines de StEtienne, 158 Cours Fauriel, 42023 St-Etienne Cedex, France

Corresponding author :Françoise VALDIVIESO

LPMG, CNRS UMR 5148, Centre SPIN, Ecole Nationale Supérieure des Mines de SaintEtienne, 158 Cours Fauriel, 42023 St-Etienne Cedex, FRANCE

fvaldivieso@emse.fr

tel : $33(0) 4774202$ 91, fax : $33(0) 477499694$

\begin{abstract}
A kinetic study of the transformation of $\mathrm{HGdP}_{2} \mathrm{O}_{7} .1 .5 \mathrm{H}_{2} \mathrm{O}$ into $\mathrm{HGdP}_{2} \mathrm{O}_{7} .0 .5 \mathrm{H}_{2} \mathrm{O}$ has been achieved by means of isothermal thermogravimetry experiments under controlled water vapour pressure. This pressure was found to have an accelerating effect upon the rate of reaction. The kinetic curves giving the extent of reaction versus time can be described using a Mampel's model. Via this modeling, values of surfacic growth rate and frequency of nucleation have been determined.
\end{abstract}

Keywords : Hydrates ; Isothermal gravimetry ; Kinetic modeling.

\section{Introduction}

Lanthanide phosphates have a wide range of applications, particularly due to their optical properties. Thus, the way of synthesis of a series of lanthanide phosphates $\mathrm{HLnP}_{2} \mathrm{O}_{7} . \mathrm{nH}_{2} \mathrm{O}$ monocrystals has been studied, in order to determine their crystalline structure and to clarify their decomposition process. Finally, their optical and electrical properties have been characterized [3]. Recently, Chehimi et al. described [1], for the first time, the chemical preparation and structure of a lanthanide diphosphate acid: $\mathrm{HGdP}_{2} \mathrm{O}_{7}-3 \mathrm{H}_{2} \mathrm{O}$. It was obtained as a single crystal. Its structure has been solved in the triclinic system $(Z=2)$. It was found out that its atomic arrangement consists of pairs of $\mathrm{HP}_{2} \mathrm{O}_{7^{3-}}$ anions interconnected by strong hydrogen bonds, and that different types of hydrogen bondings exist. Consequently different kinds of water molecules can be distinguished in the formula unit, in fact:

* one water molecule is engaged in two hydrogen bonds with two external oxygen atoms of the $\mathrm{P}_{2} \mathrm{O}_{7}$ groups,

* a second water molecule is involved in only one hydrogen bond with an external oxygen atom of the $\mathrm{P}_{2} \mathrm{O}_{7}$ groups and situated in the Gd coordination sphere,

* a third water molecule is characterized by its high thermal agitation. This one is not engaged in any interaction and does not belong to Gd coordination.

Bearing in mind the results of thermal analysis, X-Ray powder diffraction and IR spectroscopic studies, the thermal behavior of $\mathrm{HGdP}_{2} \mathrm{O}_{7}, 3 \mathrm{H}_{2} \mathrm{O}$ in the range $20-500^{\circ} \mathrm{C}$, as proposed by Chehimi et al. [2], can be represented schematically by the following steps :

(1) $\mathrm{HGdP}_{2} \mathrm{O}_{7} .3 \mathrm{H}_{2} \mathrm{O}=\mathrm{HGdP}_{2} \mathrm{O}_{7} .1 .5 \mathrm{H}_{2} \mathrm{O}+1.5 \mathrm{H}_{2} \mathrm{O}$

$\left(71-150^{\circ} \mathrm{C}\right)$

(2) $\mathrm{HGdP}_{2} \mathrm{O}_{7} \cdot 1 \cdot 5 \mathrm{H}_{2} \mathrm{O}=\mathrm{HGdP}_{2} \mathrm{O}_{7} \cdot 0.5 \mathrm{H}_{2} \mathrm{O}+\mathrm{H}_{2} \mathrm{O}$

(3) $\mathrm{HGdP}_{2} \mathrm{O}_{7} \cdot 0.5 \mathrm{H}_{2} \mathrm{O}=\mathrm{HGdP}_{2} \mathrm{O}_{7}+0.5 \mathrm{H}_{2} \mathrm{O}$

$\left(365-500^{\circ} \mathrm{C}\right)$ 
The aim of our work is to determine the mechanism of water elimination in $\mathrm{HGdP}_{2} \mathrm{O}_{7} .3 \mathrm{H}_{2} \mathrm{O}$ and to find out the optimal conditions to obtain its intermediate hydrates and anhydrous salt.

In this paper we intend to study the influence of water pressure upon the rate of the second step of $\mathrm{HGdP}_{2} \mathrm{O}_{7} .3 \mathrm{H}_{2} \mathrm{O}$ dehydration (2). Thermal evolution of this material has been followed by temperature-programmed thermogravimetry under $P_{\mathrm{H}_{2} \mathrm{O}}=5 \mathrm{hPa}$ and in situ XRD, in order to determine the temperature and pressure conditions leading to the intermediate hydrates containing $1.5 \mathrm{H}_{2} \mathrm{O}$ and $0.5 \mathrm{H}_{2} \mathrm{O}$. Then, isothermal dehydration according to reaction (2) has been carried out under different fixed water vapour pressures. A kinetic model based on nucleation and growth steps is proposed to fit the corresponding kinetic curves.

\section{Materials and experimental set up}

The preparation of $\mathrm{HGdP}_{2} \mathrm{O}_{7} .3 \mathrm{H}_{2} \mathrm{O}$ was described by Chehimi et al [2]. The authors succeeded in obtaining crystals with an average size of $40 \mu \mathrm{m}$ x120 $\mu \mathrm{m}$, and a thickness of $10 \mu \mathrm{m}$ (Fig. 1).

In situ XRD measurements are made using "BRUKER D8 Advance" (Cu- $\mathrm{K}_{\alpha}$ radiation, $1.5406 \AA$ - wave length).

Decomposition experiments were carried out in a symmetrical thermoanalyser (SETARAM TAG 16) (Fig. 2), using 5mg of grounded sample placed in an alumina crucible (due to this small quantity, the whole powder is in contact with the surrounding atmosphere, which allows to avoid the problems of mass and heat transfer through the sample). In both furnaces, the gas flow is composed of two flows : the carrier gas (He) with a flow of 2,8 $1 . \mathrm{h}^{-1}$ is introduced at the top of the furnace, the auxiliary gas $\left(1.2 \mathrm{l}^{-1} \mathrm{~h}^{-1}\right)$ consisting of helium and water vapour is introduced at the bottom. In such way, the head of thermobalance is protected from water vapour. The system is purged with helium before each experiment. Sudden changes in water vapour pressure, fixed by a thermoregulated water bath, are carried out by means of two baths.

\section{Results}

\subsection{Temperature-programmed Thermogravimetry}

The TG curve (Fig. 3), obtained at a very slow heating rate of $1 \mathrm{~K} \cdot \mathrm{min}^{-1}$, illustrates the dehydration of $\mathrm{HGdP}_{2} \mathrm{O}_{7} \cdot 3 \mathrm{H}_{2} \mathrm{O}$ when heated under $\mathrm{P}_{\mathrm{H} 2 \mathrm{O}}=5 \mathrm{hPa}$.

The three stages described in the bibliography [2] occur as follows : between A$\mathrm{B}, \mathrm{B}-\mathrm{C}$ and C-D. The theoretical weight loss corresponding to the A-B stage is $7 \%$, the observed one is about $8 \%$. This difference is probably due to water adsorbed at the surface of the powder, coming from ambient air. The following weight losses (B-C and $\mathrm{C}-\mathrm{D})$ are in agreement with the theoretical ones.

As it can be observed the first and third stages (A-B) and (C-D) are composed of at least two steps. Only the second stage (B-C) occurs in a single step (Fig. 3). Its onset temperature was found to be in the range $100-130^{\circ} \mathrm{C}$.

\subsection{In situ XRD}

Fig. 4 gives the diffractograms obtained from $\mathrm{HGdP}_{2} \mathrm{O}_{7} \cdot 3 \mathrm{H}_{2} \mathrm{O}$ heated under helium at different temperatures. It shows that the thermal decomposition of this hydrate involves intermediate phases which are well crystallized. According to the characterization of $\mathrm{HGdP}_{2} \mathrm{O}_{7} .3 \mathrm{H}_{2} \mathrm{O}$ thermal products quoted by Chehimi [2], the patterns obtained at $105^{\circ} \mathrm{C}$ and $200^{\circ} \mathrm{C}$ can be attributed to $\mathrm{HGdP}_{2} \mathrm{O}_{7} \cdot 1.5 \mathrm{H}_{2} \mathrm{O}$ and $\mathrm{HGdP}_{2} \mathrm{O}_{7} .0 .5 \mathrm{H}_{2} \mathrm{O}$. According to the TG-curves (Fig. 3), these phases are obtained respectively after calcination of $\mathrm{HGdP}_{2} \mathrm{O}_{7} .3 \mathrm{H}_{2} \mathrm{O}$ at $135^{\circ} \mathrm{C}(\mathrm{B})$ and $205^{\circ} \mathrm{C}(\mathrm{C})$. 


\subsection{Experimental kinetic curves}

The isothermal thermogravimetry technique was used to obtain the dehydration TG curves of $\mathrm{HGdP}_{2} \mathrm{O}_{7} .3 \mathrm{H}_{2} \mathrm{O}$ according to reaction (2). It was also used to obtain the hydrate $\mathrm{HGdP}_{2} \mathrm{O}_{7} .1 .5 \mathrm{H}_{2} \mathrm{O}$. However the storage of the latter was not easy because it rehydrates as soon as leaving the thermobalance. Thus, $\mathrm{HGdP}_{2} \mathrm{O}_{7} .1 .5 \mathrm{H}_{2} \mathrm{O}$ was prepared in-situ from $\mathrm{HGdP}_{2} \mathrm{O}_{7} .3 \mathrm{H}_{2} \mathrm{O}$, in isothermal and isobaric conditions : $\mathrm{T}=95^{\circ} \mathrm{C}, \mathrm{P}_{\mathrm{H} 2 \mathrm{O}}=5$ $\mathrm{hPa}$ for 3 hours.

When the mass loss is stabilized at $95^{\circ} \mathrm{C}$, corresponding to $\mathrm{HGdP}_{2} \mathrm{O}_{7} .1 .5 \mathrm{H}_{2} \mathrm{O}$ formation, the temperature is raised to $160^{\circ} \mathrm{C}$ and water vapour pressure is suddenly modified to 20 or $50 \mathrm{hPa}$. A thermogravimetric curve is represented in Fig. 5, showing the in-situ formation of $\mathrm{HGdP}_{2} \mathrm{O}_{7} .1 .5 \mathrm{H}_{2} \mathrm{O}$ (the experimental weight loss is about $6.77 \%$, whereas the theoretical one is $7 \%$ ) and its dehydration to $\mathrm{HGdP}_{2} \mathrm{O}_{7} .0 .5 \mathrm{H}_{2} \mathrm{O}$ (the experimental weight loss is about $5.3 \%$ (from the sample mass obtained at $95^{\circ} \mathrm{C}$ ), the theoretical one being 5.01\%). These values of weight loss show that the dehydration into $\mathrm{HGdP}_{2} \mathrm{O}_{7} \cdot 1.5 \mathrm{H}_{2} \mathrm{O}$ is not finished at the end of the isotherm at $95^{\circ} \mathrm{C}$, it ends during the temperature increase up to $160^{\circ} \mathrm{C}$. The total weight loss in Fig. $5(11.7 \%)$ is equal to the theoretical one corresponding to the dehydration of $\mathrm{HGdP}_{2} \mathrm{O}_{7} .1 .5 \mathrm{H}_{2} \mathrm{O}$ into

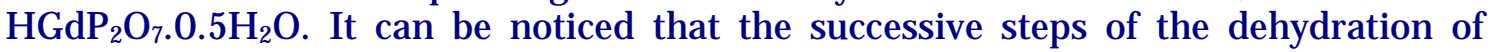
$\mathrm{HGdP}_{2} \mathrm{O}_{7} .3 \mathrm{H}_{2} \mathrm{O}$ could be separated very well with SCTA experiments, under controlled partial pressure of water vapour [3].

The TG curves corresponding to reaction (2) were converted into kinetic curves

6.a) giving the fractional conversion $\alpha$ versus time, in which $\alpha$ is defined by Eq.1:

$$
\alpha(\mathrm{t})=\Delta m(t) / \Delta m_{t h}
$$

$\Delta \mathrm{m}(\mathrm{t})$ is the mass loss at time $\mathrm{t}$ and $\Delta \mathrm{m}_{\text {th }}$ is the theoretical total mass loss (5.01\%). The starting point in these curves is obtained from the final experimental mass, taking into account the theoretical weight loss $\left(\Delta m_{t h}\right)$.

In Fig. 6, only the isothermal part of TG-curves is shown, the starting point being the time at which the sample temperature has effectively reached $160^{\circ} \mathrm{C}$.

The derivative of $\alpha$ versus time, $d \alpha / d t$, is represented in Fig 6.b as a function of $\alpha$. At the beginning $(0<\alpha<0.2)$ it seems that two reactions take place simultaneously,

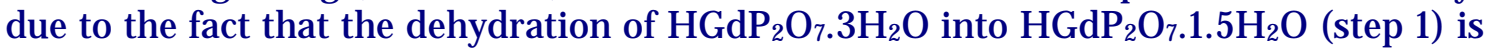
not finished at the end of the isotherm at $95^{\circ} \mathrm{C}$, which gives a contribution to the measured rate.

An accelerating effect of water vapour pressure is observed on reaction (2) in the range 5-50 hPa.

The sigmoïdal shape of the curves giving the fractional conversion versus time indicates that the dehydration reaction involves a competition between the processes of nucleation and growth of the $\mathrm{HGdP}_{2} \mathrm{O}_{7} .0 .5 \mathrm{H}_{2} \mathrm{O}$ phase [4].

\subsection{Kinetic Modelling}

Fig. 7 shows a particle of $\mathrm{HGdP}_{2} \mathrm{O}_{7} .1 .5 \mathrm{H}_{2} \mathrm{O}$ obtained from $\mathrm{HGdP}_{2} \mathrm{O}_{7} \cdot 3 \mathrm{H}_{2} \mathrm{O}$ heated at $95^{\circ} \mathrm{C}$ under $\mathrm{P}_{\mathrm{H} 2 \mathrm{O}}=5 \mathrm{hPa}$, which presents a parallelepipedic shape (as in the starting powder in Fig. 1). For the kinetic modeling of the transformation, in order to simplify the calculations, $\mathrm{HGdP}_{2} \mathrm{O}_{7} .1 .5 \mathrm{H}_{2} \mathrm{O}$ will be assimilated to a cylinder, with a mean radius of $20 \mu \mathrm{m}$ and a mean height equal to $120 \mu \mathrm{m}$ (we could also have considered plates, but in that case the thickness of the grains is neglected besides the other dimensions, which is not true here). The molar volume $V_{m}$ of $\mathrm{HGdP}_{2} \mathrm{O}_{7} .1 .5 \mathrm{H}_{2} \mathrm{O}$ is assumed to be similar to the $\mathrm{HGdP}_{2} \mathrm{O}_{7} .3 \mathrm{H}_{2} \mathrm{O}$ one $\left(1,298.10^{-4} \mathrm{~m}^{3}\right.$. $\left.\mathrm{mol}^{-1}\right)$. 
In order to account for the sigmoidal shape of the kinetic curves, we used a Mampel model $[5,6]$ which involves a surface nucleation at different times, followed by isotropic growth of the nuclei. The spherical interface advances inwards the particle. The rate limiting step of the growth process is assumed to be located at the internal interface (between the $\mathrm{HGdP}_{2} \mathrm{O}_{7 .} 1.5 \mathrm{H}_{2} \mathrm{O}$ and $\mathrm{HGdP}_{2} \mathrm{O}_{7} .0 .5 \mathrm{H}_{2} \mathrm{O}$ phases).

At a given time, the particle shows several nuclei of various dimensions growing simultaneously. A schematic representation of a particle during its transformation is given in Fig. 8, and Fig. 9 shows a grain during the reaction $(\alpha=0.4)$, in which some transformed areas can be observed.

As previously done [5-8], it is useful to use dimensionless numbers which allow computerized calculations of the reaction rate and the extent of reaction. The calculations are detailed in Appendix.

The dimensionless numbers are $\theta$ (dimensionless time) and a parameter $\mathrm{A}$, defined by :

$$
\theta=\frac{V_{m} \phi}{r_{0}} \mathrm{t}
$$

$\mathrm{A}=\frac{s_{0} r_{0} \gamma}{V_{m} \phi}$

in which $\mathrm{V}_{\mathrm{m}}$ is the molar volume of the initial solid $\left(\mathrm{HGdP}_{2} \mathrm{O}_{7} .1 .5 \mathrm{H}_{2} \mathrm{O}\right)$, $\mathrm{s}_{\mathrm{o}}$ is the initial surface of the grains, $r_{0}$ is the radius of the cylindrical grains, $\phi$ is the areic rate of growth $\left(\right.$ mole. $\left.\mathrm{m}^{-2} \cdot \mathrm{s}^{-1}\right)$ and $\gamma$ is the areic frequency of nucleation (nuclei. $\mathrm{m}^{-2} \cdot \mathrm{s}^{-1}$ ).

This leads to an expression of $\alpha$ and $\frac{d \alpha}{d t}$ as a function of $\theta$, for any value of the parameter A. A software 'CIN' has been developed in the Ecole des Mines de SaintEtienne to calculate numerically under 'Matlab' these expressions.

When A is varied, different curves of $\frac{d \alpha}{d t}$ vs $\alpha$ can be calculated, some curves are represented in Fig. 10 : they give the "reduced rate " (ratio of the rate $\frac{d \alpha}{d t}$ to the value of this rate when $\alpha$ is equal to $0.5:\left(\frac{d \alpha}{d \theta}\right)_{\alpha=0.5}$ ) versus $\alpha$, and show that the shape of the curves (and particularly the position of the maximum rate) is greatly dependant on the value of the A parameter.

The comparison between the experiments and the model is achieved by plotting the experimental and calculated reduced rates versus $\alpha$ for each experiment, and finding the value of $A$ which gives the best agreement between the curves.

Fig. 11 represents the experimental and calculated reduced rates versus $\alpha$, for various partial pressures in water vapour $\left(\mathrm{P}_{\mathrm{H} 2 \mathrm{O}}=5\right.$ and $\left.20 \mathrm{hPa}\right)$.

It can be seen that the calculated curves are not very well superimposed to the experimental ones. However, the general trend is reproduced, the difference between the curves can be due to the fact that :

* reaction (2) is not well separated from the previous step (1) $(\alpha \leq 0.1)$,

* a cylindrical shape is taken into account in the model rather than a parallelepipedic one.

The value of A can be determined from the best agreement between experimental and calculated rate, considering the position of the maximal rate and the variation in the slope of the curves in the range of $\alpha \approx 0.6-0.7$. 
The interest of the kinetic analysis of Mampel is that it gives the opportunity of determining the values of the kinetic constants related to nucleation $(\gamma)$ and growth $(\phi)$. This is not possible with for example the Avrami-Erofeev analysis, which is often used to account for sigmoïdal kinetic curves. It should be emphasized that these values of $\gamma$ and $\phi$ are areic quantities, so they do not depend on the geometric characteristics of the solid (shape of the grains, size...). However, they may depend on the experimental variables such as temperature and partial pressures, and also on the chemical properties of the solid phase (impurities, defects...).

Once the value of A has been determined for a given experiment, the value of $\phi$ can be deduced from the linear relationship between $\theta$ (reduced time) and $t$ (real time), given in (Eq. 2). Then, using the value of A leads to the frequency of nucleation $\gamma$.

The values of $\gamma$ and $\Phi$ obtained for various isobaric experiments (at 5, 20 and $50 \mathrm{hPa}$ ) have been reported as a function of water vapour pressure on Fig. 12.

It can be seen (Fig. 12) that both $\gamma$ and $\Phi$ are found to increase with increasing water vapour pressure.

The origin of the kinetic influence of water vapour pressure on this kind of reaction (dehydration) has already been attributed to the so-called Smith-Topley effect $[9,10]$. Future experiments would be helpful to investigate this behaviour in more details, especially in a wider range of water vapour pressure.

\section{Conclusions}

The kinetic curves of partial $\mathrm{HGdP}_{2} \mathrm{O}_{7} .1 .5 \mathrm{H}_{2} \mathrm{O}$ dehydration to $\mathrm{HGdP}_{2} \mathrm{O}_{7} .0 .5 \mathrm{H}_{2} \mathrm{O}$ under various water vapour pressures were obtained by isothermal gravimetry. The curves giving the fractional conversion $\alpha$ vs time exhibited a sigmoidal shape, which shows that a competition between the processes of nucleation and growth of the $\mathrm{HGdP}_{2} \mathrm{O}_{7} .0 .5 \mathrm{H}_{2} \mathrm{O}$ phase has to be taken into account. A model based on Mampel's model has been used, considering a cylindrical geometry for the grains of the powder. From this model, the variations of the growth reactivity and the frequency of nucleation with the water vapour pressure could be obtained: an accelerating effect of water vapour pressure is observed on both processes of nucleation and growth.

Further work is necessary to propose a mechanism in elementary steps (adsorptiondesorption steps, interface steps, diffusions), describing the growth of $\mathrm{HGdP}_{2} \mathrm{O}_{7} .0 .5 \mathrm{H}_{2} \mathrm{O}$, and involving its point defects. From such a mechanism, and using the assumption of the rate-determining step, it would be possible to calculate theoretical laws for $\phi\left(\mathrm{P}_{\mathrm{H} 2 \mathrm{O}}\right)$. The comparison of theses laws with the experimental results would allow to determine the rate-limiting step (which should be located at the internal interface to be coherent with the Mampel's assumptions) and to validate the growth mechanism.

Similarly, a nucleation mechanism could be proposed, to account for the variations of $\gamma$ with $\mathrm{P}_{\mathrm{H} 2 \mathrm{O}}$. 


\section{References}

[1] F.Chehimi-Moumen, D. Ben Hassen-Chehimi, M.Ferid, M.Trabelsi-Ayadi, Mat. Res. Bull. 36(1-2) (2001) 365-373.

[2] F.Chehimi-Moumen, D. Ben Hassen-Chehimi, M.Ferid and M.Trabelsi-Ayadi, Mat. Res. Bull., 36(12) (2001) 2175-2181.

[3] F.Chehimi-Moumen, PhD thesis, Bizerte (Tunisia), 2002.

[4] M. Soustelle, M.Pijolat, Solid State Ionics 95 (1997) 33-40.

[5] K.L.Mampel, Z. Phys. Chem. A187 (1940) 43-57 and 235-249.

[6] B. Delmon, Introduction à la Cinétique Hétérogène, Technip, Paris, 1969.

[7] F. Valdivieso, V. Bouineau, M.Pijolat, M. Soustelle, Solid State Ionics 101-103 (1997) 1299-1303.

[8] J.P. Viricelle, M. Pijolat, C. Zing, M. Soustelle, J. Chem. Soc. Faraday Trans. 91(24) (1995) 4431-4435.

[9] B. Topley, M. L. Smith, J . Chem. Soc. (1935) 321.

[10] G. Bertrand, M. Lallemant, G. Watelle-Marion, J. Inorg. Nucl. Chem. 36 (1974) 1303. 


\section{Appendix}

The Mampel model [4] describes a random nucleation process at the surface of the grains and the isotropic growth of the nuclei. The nuclei are assumed to appear on the surface of grains and to grow inward. The rate limiting step takes place at the internal interface (between the starting phase and the growing new phase) and the expansion coefficient is equal to 1 . Furthermore, pressure and temperature are constant versus time. The nucleation is assumed to be a space-time Poisson process, with a mean areic frequency of nucleation $\gamma$ which is expressed as a number of nuclei per unit of time and per unit of surface area. The growth process is deterministic and spatially homogeneous. The areic rate of radial growth $\phi$, is constant versus time in the case of isothermal and isobaric reactions. The rate $\phi$ is given in moles per unit of time and per unit of surface area.

As previously done by other authors [3, 6, 7], the geometrical model intends to find the values of areic frequency of nucleation $\gamma\left(\right.$ nuclei. $\left.\mathrm{m}^{-2} \cdot \mathrm{s}^{-1}\right)$ and of the areic reactivity of growth (moles. $\left.\mathrm{m}^{-2} \cdot \mathrm{s}^{-1}\right)$ in any conditions of temperature and partial pressure.

Let us consider the transformed volume, by calculating the intersection between a spherical nucleus and a cylinder of radius $\rho<\mathrm{r}_{0}$ (Fig. 12).

Furthermore let us consider $w(\rho, t)$ the fractional non-transformed surface, which is introduced in order to avoid overlapping between different nuclei, given by :

$w(\rho, t)=\exp -\int N . S_{g}(t, \tau, \rho) d \tau$

where $\mathrm{N}$ is the number of intersecting surfaces between nuclei and a cylinder of radius $\rho, S_{g}(t, \tau, \rho)$ is the intersection area between the spherical nuclei and the cylinder of radius $\rho<r_{0}$.

According to the time $\tau$ at which the nuclei appeared (Fig. 12), $\mathrm{S}_{\mathrm{g}}$ and $\mathrm{N}$ take different expressions (Table. A1).

The extent of conversion, $\alpha$, takes the following form :

$\alpha=\int_{0}^{r_{0}} \frac{2 \rho}{r_{0}}(1-\mathrm{w}(\rho, \mathrm{t})) \mathrm{d} \rho$

This allows a computerized calculation of the reaction rate (derivative of fractional conversion $\alpha$ ).

We introduce the dimensionless numbers which are denoted $\eta_{\text {(which corresponds to }}$ the time $\tau$, reduced time replacing $\mathrm{t}$ ) and A (called the model parameter), and are defined by :

$$
\eta=\frac{V_{m} \phi}{r_{0}} \tau \quad \theta=\frac{V_{m} \phi}{r_{0}} \mathrm{t} \quad \mathrm{A}=\frac{s_{0} r_{0} \gamma}{V_{m} \phi}
$$

The calculations lead to the expressions giving $d \alpha / d \theta(\theta)$, reported in Table A2. 


\section{Figures captions}

Fig. 1: Photograph of $\mathrm{HGdP}_{2} \mathrm{O}_{7} .3 \mathrm{H}_{2} \mathrm{O}$.

Fig. 2 : Thermobalance used to decompose $\mathrm{HGdP}_{2} \mathrm{O}_{7} \cdot 3 \mathrm{H}_{2} \mathrm{O}$ in $\mathrm{H}_{2} \mathrm{O}$ atmosphere.

Fig. 3 : Temperature- programmed TG under $\mathrm{P}_{\mathrm{H} 2 \mathrm{O}}=5 \mathrm{hPa}$.

Fig. 4 : XRD patterns of $\mathrm{HGdP}_{2} \mathrm{O}_{7} \cdot 3 \mathrm{H}_{2} \mathrm{O}$ heated in situ at $3^{\circ} \mathrm{C} \mathrm{min}^{-1}$ under helium.

Fig. 5 : Isothermal TG curve of $\mathrm{HGdP}_{2} \mathrm{O}_{7} \cdot 3 \mathrm{H}_{2} \mathrm{O}$ under $\mathrm{P}_{\mathrm{H} 2 \mathrm{O}}=5 \mathrm{hPa}$ at $95^{\circ} \mathrm{C}$ then at $160^{\circ} \mathrm{C}$.

Fig. 6 : Kinetic curves of partial dehydration of $\mathrm{HGdP}_{2} \mathrm{O}_{7} .1 .5 \mathrm{H}_{2} \mathrm{O}$ for different water vapour pressures $(5,20,50 \mathrm{hPa}$ ) : Fractional conversion $\alpha$ vs time (a), and derivative of $\alpha$ vs $\alpha(b)$.

Fig. 7 : Photograph of $\mathrm{HGdP}_{2} \mathrm{O}_{7} .3 \mathrm{H}_{2} \mathrm{O}$ heated $3 \mathrm{~h}$ at $95^{\circ} \mathrm{C}$ under $\mathrm{P}_{\mathrm{H} 2 \mathrm{O}}=5 \mathrm{hPa}$.

Fig. 8 : Schematic representation of the state of a particle a during the reaction.

Fig 9 : Photograph of $\mathrm{HGdP}_{2} \mathrm{O}_{7} \cdot 1.5 \mathrm{H}_{2} \mathrm{O}$ during its dehydration at $160^{\circ} \mathrm{C}(\alpha=0.4)$, under $\mathrm{P}_{\mathrm{H} 2 \mathrm{O}}=5 \mathrm{hPa}$.

Fig. 10 : Examples of calculated kinetic curves for various values of the parameter A of the Mampel's model $(\mathrm{A}=0.01,0.1,1,100,1000)$.

Fig. 11 : Comparison between the experimental (-) and calculated (---) curves of the reduced rates versus $\alpha$, for different values of $A$.

Fig. 12 : Variations with the water vapor pressure, of the frequency of nucleation $\gamma$ and the areic rate of growth $\phi$ deduced from the kinetic modeling (ie the value of $\mathrm{A}$ corresponding to the best fit between the experimental and calculated curves, for each experiment performed at a given water vapour pressure).

Fig. 13 : Progression of nuclei which appeared at different times $\tau$.

\section{Tables captions}

Table A1 : Expressions of $\mathrm{S}_{\mathrm{g}}$ and $\mathrm{N}$ according to the time $\tau$ at which the nuclei appeared.

\begin{tabular}{|c|c|c|}
\hline time at which nuclei appeared & 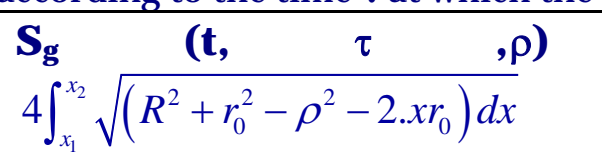 & $=$ \\
\hline (1) $\tau>t-\frac{r_{0}-\rho}{V_{m} \phi}$ & 0 & 0 \\
\hline (2) $t-\frac{r_{0}+\rho}{V_{m} \phi}<\tau<t-\frac{2 r_{0}}{V_{m} \phi}$ & $\begin{array}{l}-\mathrm{x}_{1}=\mathrm{r}_{0}-\rho \\
-\mathrm{x}_{2}=\frac{1}{2 r_{0}}\left(\mathrm{~V}_{m}^{2} \mathrm{v}^{2}(\mathrm{t}-\tau)^{2}+\mathrm{r}_{0}^{2}-\rho^{2}\right)\end{array}$ & $\frac{r_{0}}{\rho} \gamma$ \\
\hline (3) $\tau<t-\frac{r_{0}+\rho}{V_{m} \phi}$ & $\begin{array}{l}-x_{1}=r_{0}-\rho \\
-x_{2}=r_{0}+\rho\end{array}$ & $\frac{r_{0}}{\rho} \gamma$ \\
\hline
\end{tabular}

Table A2 : Expressions of the rate calculated according to the Mampel model for cylindrical geometry 


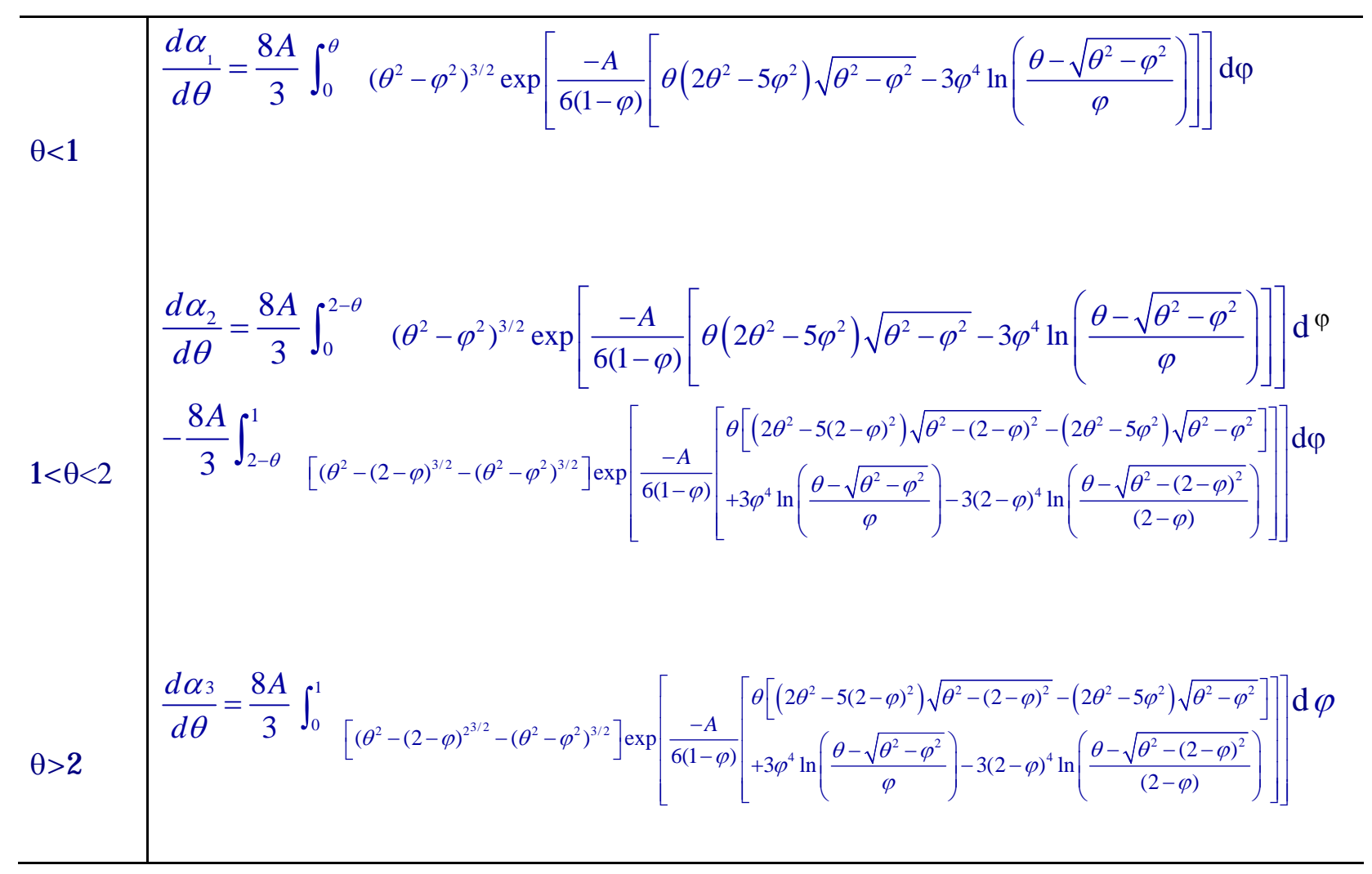

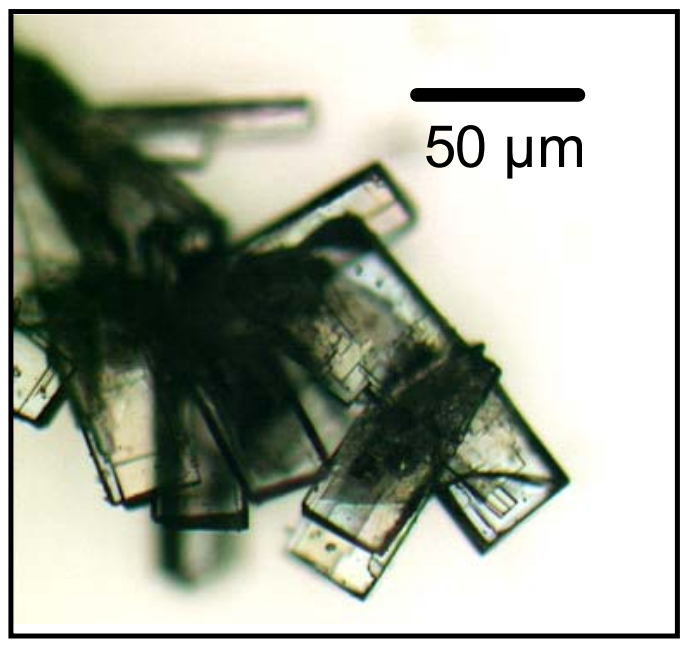

Figure 1 


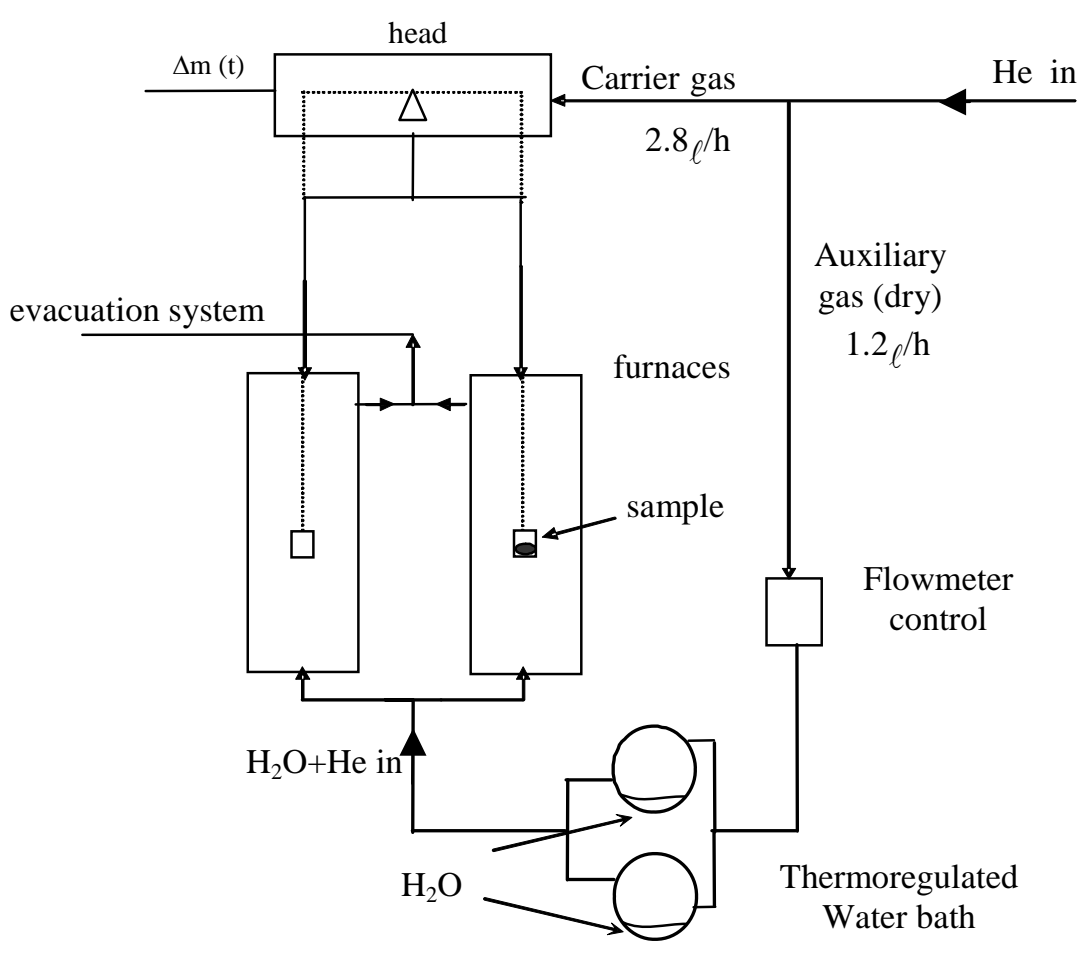

Figure 2

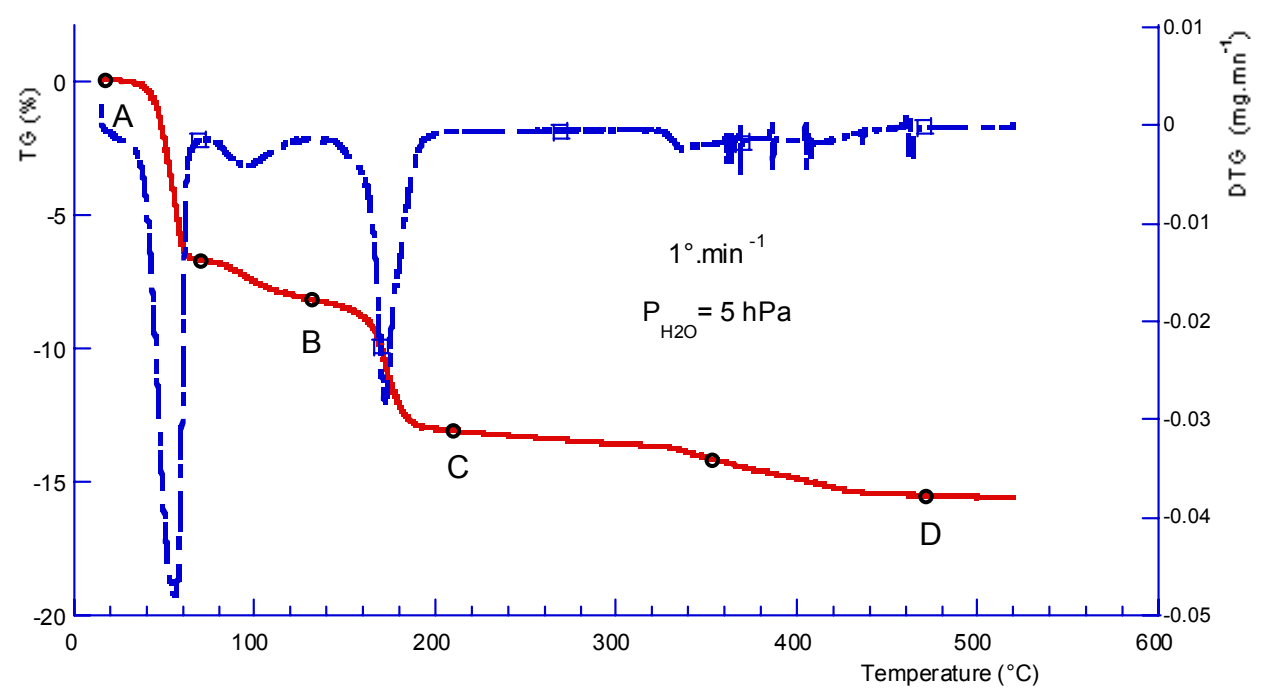

Figure 3 

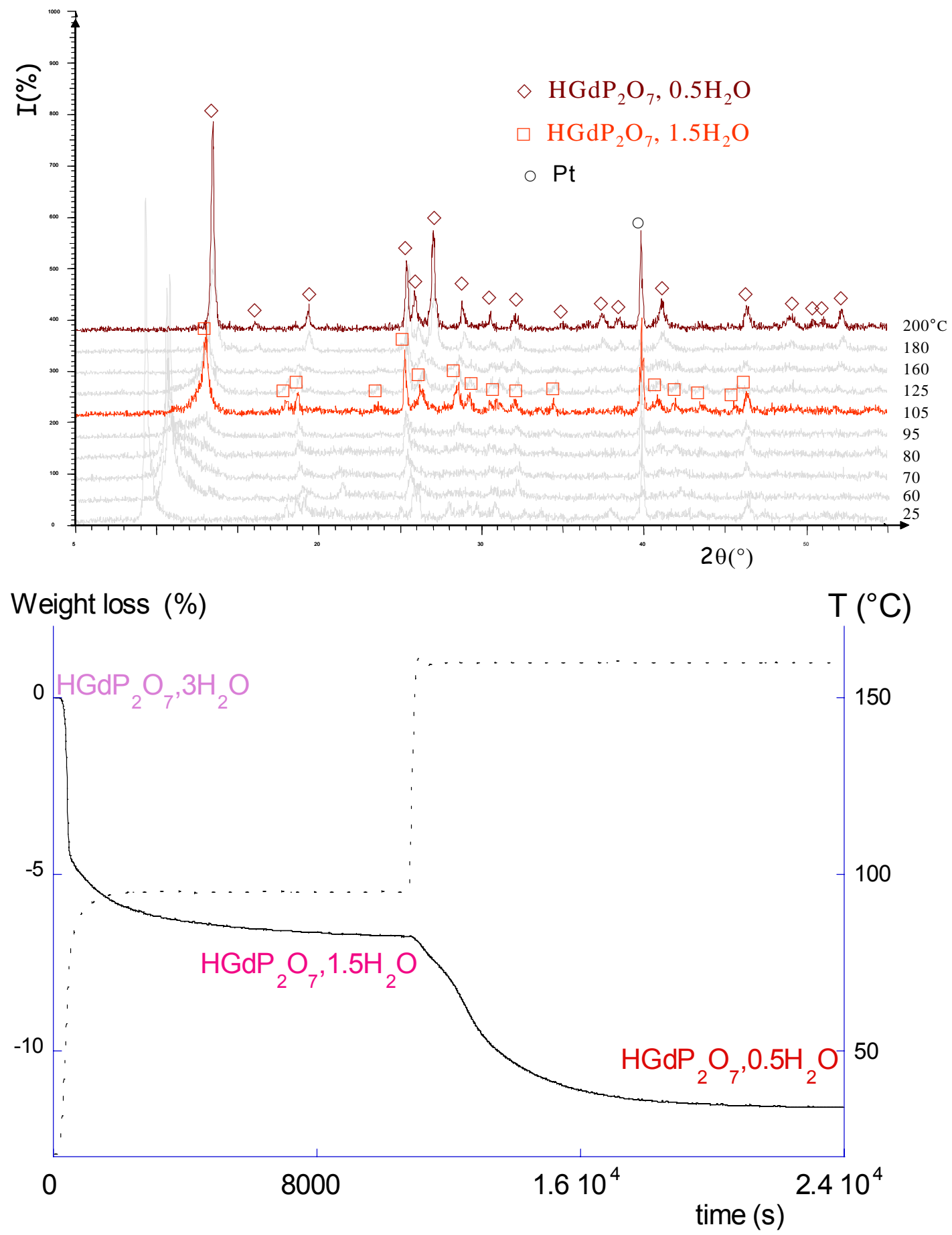

Figure 4

Pt 


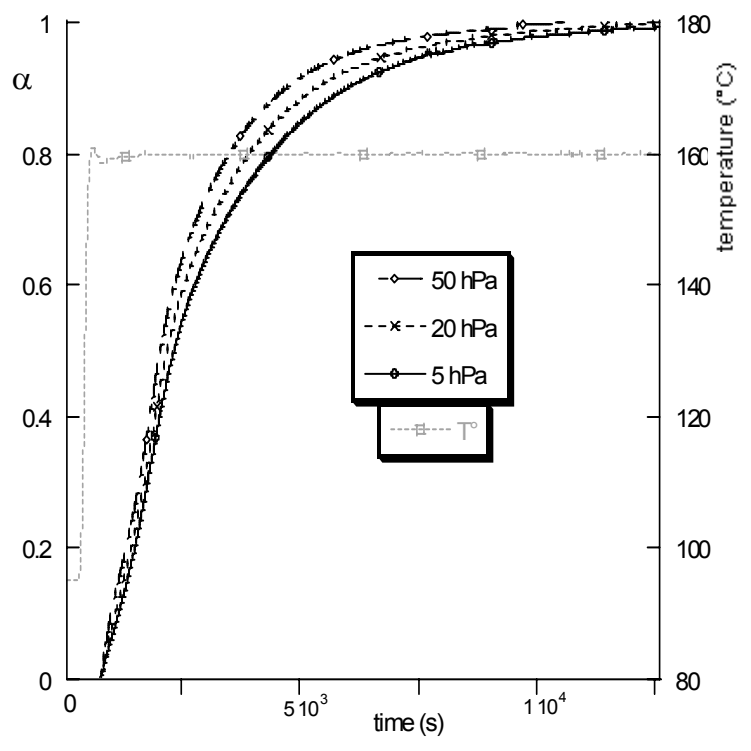

Figure 6a

Figure 6b
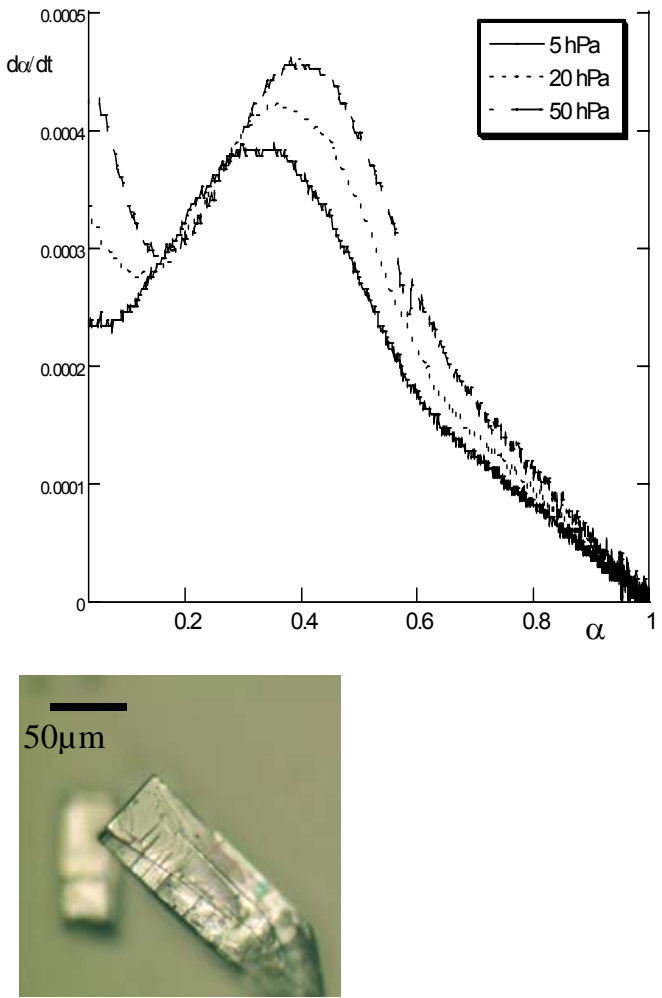

Figure 7 
Figure 8
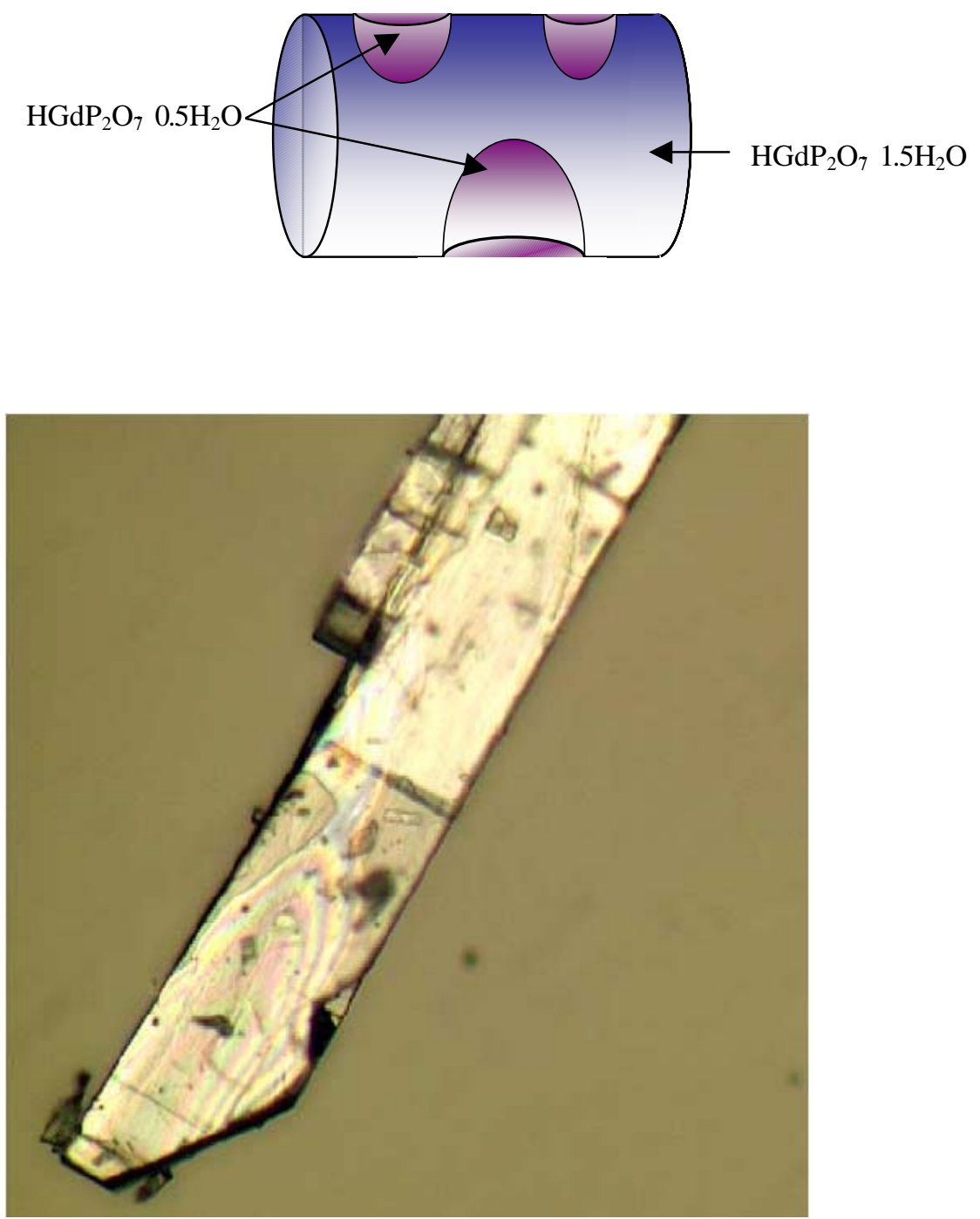

Figure 9 


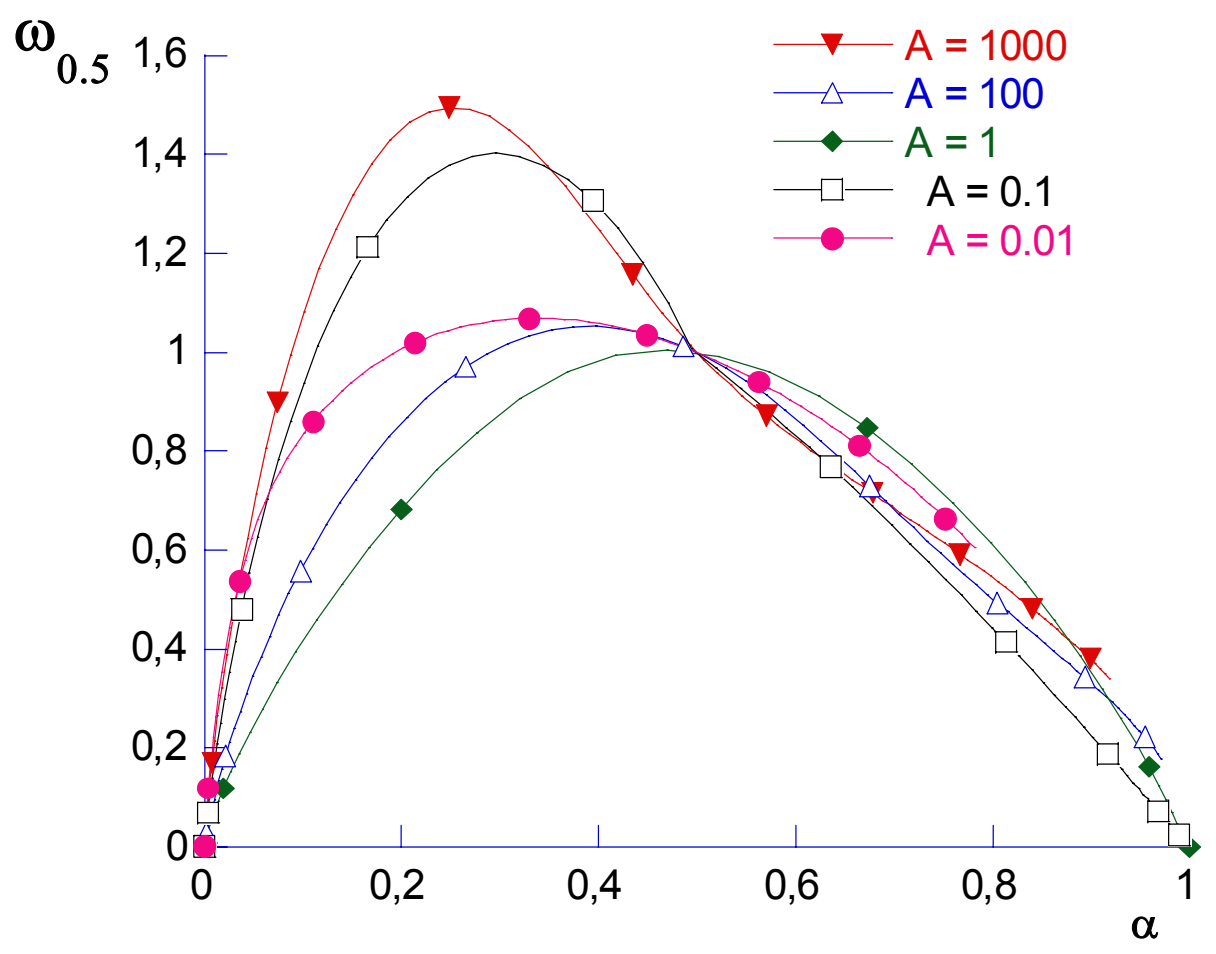

Figure 10

Figure 11

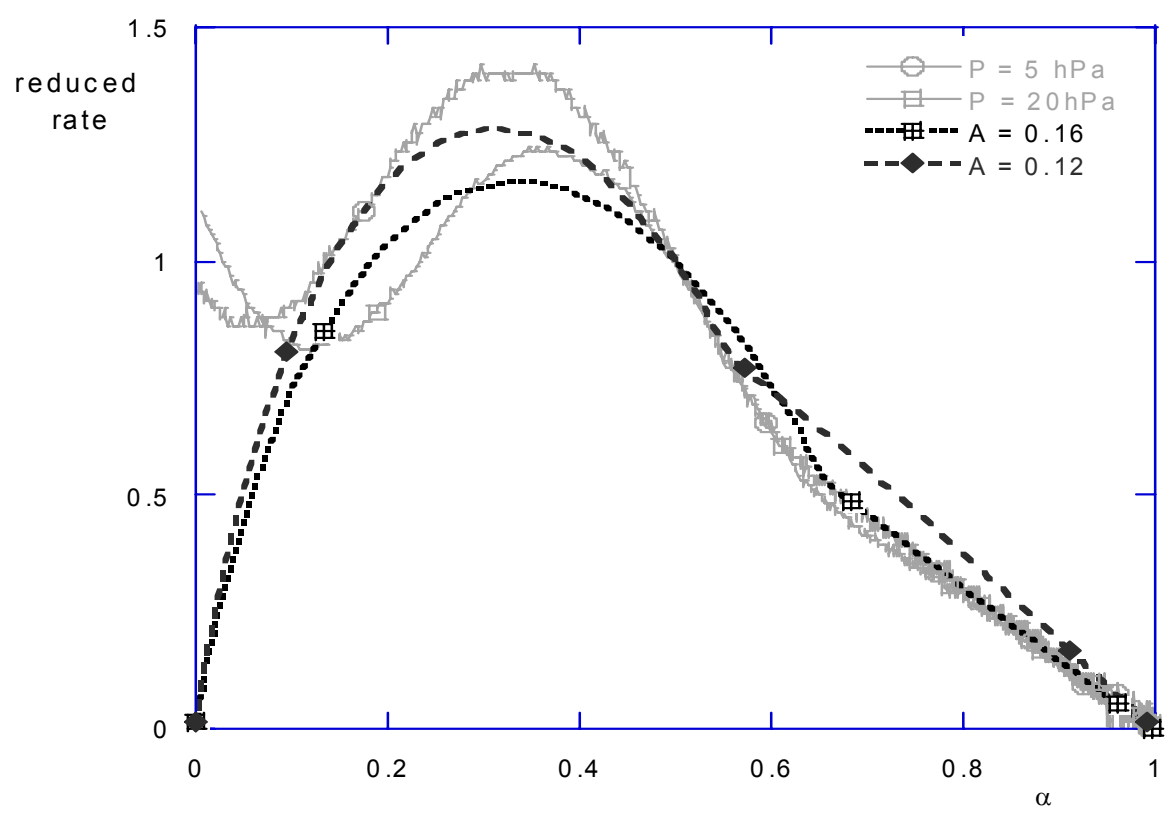


Figure 12
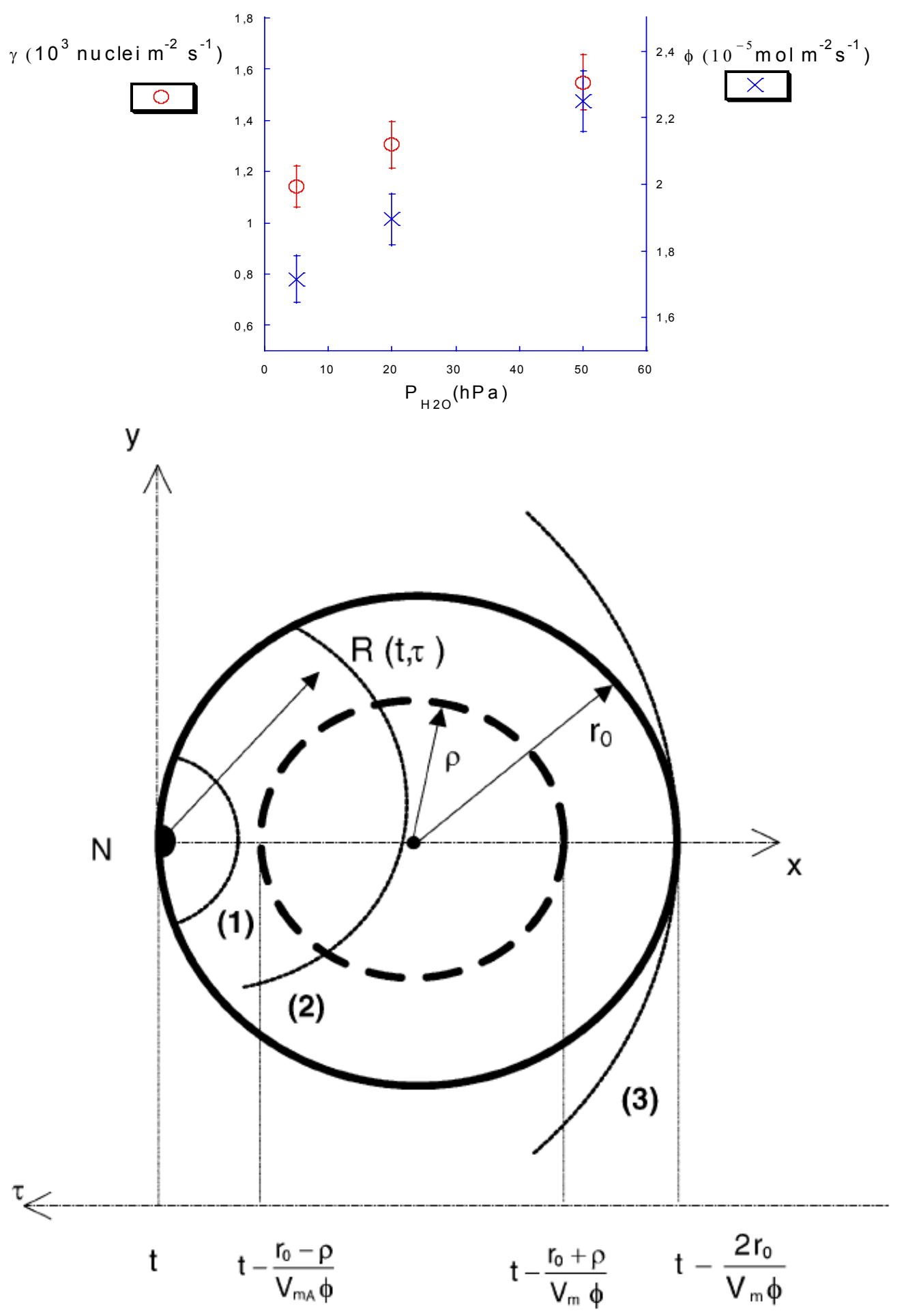

Figure 13 